\title{
A PROPOSTA DE REDAÇÃO DO ENEM: UMA ANÁLISE ARQUITETÔNICA E COMPOSICIONAL
}

\author{
JOSERLÂNDIO DA COSTA SILVA ${ }^{1}$
}

\author{
Programa de Pós-Graduação em Linguística - Universidade Federal da Paraíba \\ Conjunto Humanístico - Bloco IV - Cidade Universitária - João Pessoa-PB \\ jcsletras@hotmail.com
}

\begin{abstract}
Resumo. Neste trabalho, analisamos as propostas de redação do Exame Nacional do Ensino Médio, o ENEM, a partir das discussões do Círculo de Bakhtin sobre gêneros do discurso. A pergunta que norteou a análise foi: as propostas de redação do ENEM formam um gênero discursivo? Mostramos que, por serem enunciados que circulam regularmente em um campo específico de atuação humana, e por apresentarem estabilidade quanto ao conteúdo temático, ao estilo e à composição, podemos afirmar que as propostas de redação do ENEM são um gênero discursivo.
\end{abstract}

Palavras-chave: gênero; Bakhtin; ENEM.

\begin{abstract}
This study analyzed the essay proposals of ENEM. We took as theoretical support the theory of speech genres developed by the Bakhtin Circle. The guiding question was: do the essay proposals of ENEM constitute a discursive genre? We have demonstrated that they can be considered to be a discursive genre because they correspond to regularly produced utterances in a human interaction field, and they also have stability of content, style and composition.
\end{abstract}

Keywords: genres; Bakhtin; ENEM.

\section{Introdução}

Discutir sobre a noção de gêneros discursivos, na perspectiva do Círculo de Bakhtin, envolve um entendimento correto dos mecanismos através dos quais os sujeitos se relacionam entre si em determinado campo de interação. Assim, em uma pesquisa sobre determinado gênero, não se faz necessária somente uma descrição dos mecanismos de estruturação da língua nos enunciados que o integram, ou seja, descrever o enunciado apenas composicionalmente não nos basta. É preciso, antes de uma análise composicional, analisar o enunciado arquitetonicamente.

Segundo Brait e Pistori (2012), apesar de ser em Os gêneros do discurso, ensaio esboçado por Bakhtin nos anos 1950, que podemos encontrar a questão dos gêneros sendo discutida de maneira explícita, essa questão também é debatida em outros textos do Círculo. Um desses textos, e que para a realização do presente trabalho fornece

\footnotetext{
${ }^{1}$ Mestrando no Programa de Pós-Graduação em Linguística da Universidade Federal da Paraíba.
} 
importantes esclarecimentos, é $O$ problema do conteúdo, do material e da forma na criação literária (2010).

Ainda segundo as autoras citadas, em $O$ problema do conteúdo, do material e da forma na criação literária (2010), o aspecto que não podemos deixar de lado, quando se trata da discussão sobre gêneros do discurso, é o que se refere à diferença entre forma composicional e forma arquitetônica. Nesse sentido, como já dissemos, ao analisarmos determinado gênero, não podemos nos prender somente à descrição de suas estruturas. Agindo assim, permaneceremos apenas no terreno da forma composicional. Precisamos percorrer os aspectos que integram a forma arquitetônica, como as condições concretas que dão vida ao gênero, suas interdependências, suas relações, seus enfrentamentos dialógicos e suas posições valorativas (BRAIT; PISTORI, 2012). Conforme Sobral (2010, p. 77), "a forma arquitetônica se vincula com o projeto enunciativo do autor, com o tipo de relação com o interlocutor que ele propõe". Em outro texto, Sobral (2007, p. 111) afirma que "todo acabamento, ou totalidade arquitetônica, admite perguntas sobre quem o produziu, para quem e em que circunstâncias". Assim, são esses questionamentos que direcionam a análise da forma arquitetônica dos enunciados que são objeto de investigação neste trabalho.

Discorremos sobre as propostas de redação do Exame Nacional do Ensino Médio, doravante ENEM, a partir da perspectiva do Círculo de Bakhtin sobre gêneros. Tentaremos responder a seguinte questão: as propostas de redação do ENEM formam um gênero discursivo? Primeiramente, ressaltamos que trabalhar com a proposta de redação do ENEM é operar com um enunciado concreto. Esta noção, por si só, já é complexa. Acerca da natureza do enunciado, Bakhtin afirma que

o desconhecimento da natureza do enunciado e a relação diferente com as peculiaridades das diversidades de gêneros do discurso em qualquer campo da investigação linguística redundam em formalismo e em uma abstração exagerada, deformam a historicidade da investigação, debilitam as relações da língua com a vida. Ora, a língua passa a integrar a vida através de enunciados concretos (que a realizam), é igualmente através de enunciados concretos que a vida entra na língua. (BAKHTIN, 2011, p. 265; grifos nossos)

A partir de agora, portanto, tentaremos estabelecer essa relação entre a vida e a língua, mediante a análise de aspectos que envolvem a arquitetônica das propostas de redação do ENEM, consideradas aqui como enunciados concretos.

\section{A proposta de redação do ENEM: aspectos arquitetônicos}

Em conformidade com os escritos do Círculo bakhtiniano, que apontam para a ideia de que os gêneros nascem e se desenvolvem em eventos concretos da vida, e que "cada gênero está tematicamente orientado para a vida, para seus acontecimentos, problemas, e assim por diante" (MEDVIÉDEV, 2012, p. 195), a proposta de redação do ENEM passa a existir a partir de um momento social específico na história da Educação no Brasil. Ela está agregada a uma época de mudança no sistema de avaliação para os estudantes da reta final da educação básica, implementada em um momento histórico por 
um órgão da administração federal responsável pela Educação. Conforme esse sistema de avaliação foi adquirindo novas configurações e novos objetivos, a proposta de redação teve suas condições de produção, circulação e recepção alteradas. Assim, o tipo de texto analisado neste trabalho circula, desde 1998 , no campo ${ }^{2}$ particular da avaliação da Educação Básica brasileira através do ENEM, que promovia um novo modelo de avaliação, saindo de uma perspectiva tradicional, que media a capacidade do estudante de memorizar informações, para uma perspectiva renovada, que prioriza o pensamento crítico através de uma proposta interdisciplinar ${ }^{3}$. Nesse novo sistema avaliativo, a proposta de redação surge como uma forma de interlocução entre candidatos que estão sendo avaliados e professores que são avaliadores nesse processo.

Assim, como um enunciado próprio de determinado campo de atuação humana, as propostas de redação que integram o ENEM surgiram em 1998. Naquele ano, segundo dados do IBGE, este exame contou com apenas 115, 6 mil participantes. Em 2001, esse número subiu para um milhão e duzentos mil, um aumento expressivo, que aponta para certa complexificação do ENEM em cerca de três anos.

Em seu primeiro ano, a proposta de redação do ENEM cumpria dois objetivos principais. O primeiro era que ela contribuiria para o Ministério da Educação, MEC, avaliar o desenvolvimento da educação básica, já que a prova é realizada por alunos na reta final do nível básico de ensino. $\mathrm{O}$ segundo objetivo era proporcionar ao próprio candidato uma autoavaliação. Em 2004, o MEC instituiu o Programa Universidade para Todos, Prouni, e vinculou a concessão de bolsas em instituições de ensino superior à nota obtida no Exame. Assistimos, com isso, à popularização do ENEM, que passou a contar, na época, com mais de dois milhões de participantes.

Assim, os objetivos da proposta de redação do ENEM sofrem alterações com o passar dos anos. Inicialmente, ela apenas forneceria uma autoavaliação aos candidatos. A partir de 2004, a proposta de redação exigia destes uma recepção mais atenta, já que poderia garantir uma vaga na Universidade. Outra dessas mudanças aconteceu em 2009, quando o MEC reformulou o ENEM, e este passou a ser utilizado como forma de seleção unificada para o ingresso nas Universidades Federais. Mais uma vez, portanto, as condições de recepção da proposta de redação são alteradas. Essas mudanças complexificam o campo em que estes enunciados circulam.

$\mathrm{Na}$ introdução deste artigo, citamos um trecho do trabalho de Bakhtin (2011), no qual ele ressalta a importância de conhecermos a natureza do enunciado para então analisá-lo. No decorrer da leitura desse e de outros trabalhos do Círculo, fica claro que o enunciado é de natureza social e é parte de uma cadeia dialógica em que, ao mesmo tempo, responde e suscita outros enunciados. $\mathrm{O}$ enunciado ultrapassa os limites do texto, sendo, assim, formado por uma parte extra-verbal. Além disso, o outro que recebe o enunciado não é passivo em face deste. Bakhtin afirma que

\footnotetext{
2 Alguns estudiosos do Círculo preferem o termo "esfera" ao invés de "campo". Neste trabalho, optamos pelo termo "campo", conforme aparece na tradução do texto "Os gêneros do discurso" que estamos utilizando.

${ }^{3}$ Conferir a matriz com todas as competências e habilidades que estruturam o ENEM. Esta matriz está disponível em http://portal.inep.gov.br/web/encceja/matriz-de-competencias.
} 
toda compreensão da fala viva, do enunciado vivo é de natureza ativamente responsiva (embora o grau desse ativismo seja bastante diverso); toda compreensão é prenhe de resposta, e nessa ou naquela forma a gera obrigatoriamente: o ouvinte se torna falante. A compreensão passiva do significado do discurso ouvido é apenas um momento abstrato da compreensão ativamente responsiva real e plena, que se atualiza na subsequente resposta em voz real alta. (BAKHTIN, 2011, p. 271)

Assim, cada proposta de redação do ENEM é um enunciado concreto que suscita respostas. É concreto porque enuncia a realidade manifestando uma posição valorativa a partir de um contexto ideológico singular. O conteúdo temático das propostas das redações é elaborado a partir de acontecimentos sociais do momento. Entretanto, é ingenuidade acreditar que a realidade é apresentada de forma neutra para os candidatos. Pelo contrário, esta realidade apresentada é marcada por um posicionamento valorativo. A própria escolha do tema e a mobilização das vozes que o constroem, através do recorte de fragmentos de textos provenientes de outros campos de atuação humana, indiciam uma tomada de posição. As propostas de redações são, portanto, enunciados marcadamente ideológicos. Voloshinov (1930), discorrendo sobre os tipos de comunicação social mais conhecidos, dá-nos base para esse pensamento. Ele afirma que

considerando a vida em sociedade, nós podemos facilmente destacar, além da relação da comunicação artística, os tipos de comunicação social seguintes:

$>\quad$ As relações de produção (nas fábricas, ateliers, "kolkhozes" etc.);

$>\quad$ As relações de negócio (nas administrações, organismos públicos etc);

$>\quad$ As relações cotidianas (os encontros e as conversas na rua, nos bares, em suas casas etc.);

As relações ideológicas strictu sensu na propaganda, na escola, na ciência, na atividade filosófica, sob todas as suas formas. (VOLOSHINOV, 1930, p. 2; grifos nossos)

Como a proposta de redação do ENEM é um enunciado cujos respondentes imediatos são estudantes em sua reta final do Ensino Básico, ou que já o concluíram, ela está situada no último tipo de comunicação social elencado por Voloshinov, que envolve o das relações ideológicas no campo escolar. Ela é, portanto, um enunciado ideologicamente marcado. Nas propostas, tomam formas visões de mundo defendidas institucionalmente. Neste ponto, é preciso esclarecer que a noção de ideologia, para o Círculo, não assume um sentido negativo. Conforme afirma Faraco,

nos textos do Círculo, a palavra ideologia é usada, em geral, para designar o universo dos produtos do "espírito" humano, aquilo que algumas vezes é chamado por outros autores de cultura imaterial ou produção espiritual (talvez como herança de um pensamento idealista) e, igualmente, de formas da consciência social (num vocabulário de sabor mais materialista). Ideologia é o nome que o Círculo costuma dar, então, para o universo que engloba a arte, a ciência, a filosofia, o direito, a religião, a ética, a política, ou seja, todas as manifestações superestruturais (para usar uma certa terminologia de tradição marxista). (FARACO, 2003, p. 46; grifos do autor) 
As propostas de redação são, portanto, ideológicas, por um lado, porque são elaboradas em um campo particular de atividade humana; por outro, porque expressam um posicionamento valorativo ante a apresentação da realidade. Essa realidade apresentada resulta da tensão estabelecida entre sujeitos historicamente situados e as forças discursivas centralizadoras e descentralizadores de seu dizer. Para exemplificar o que estamos afirmando, tomemos como exemplo a proposta de redação do ENEM em 2015.

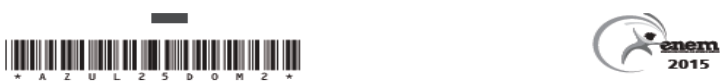

\section{PROPOSTA DE REDAÇÃO}

A partir da leitura dos textos motivadores seguintes e com base nos conhecimentos construídos ao longo de sua formação, redija texto dissertativo-argumentativo em modalidade escrita formal da língua portuguesa sobre o tema "A persistência da violência contra a mulher na sociedade brasileira", apresentando proposta de intervenção que respeite os direitos humanos. Selecione, organize e relacione, de forma coerente e coesa, argumentos e fatos para defesa de seu ponto de vista. TEXTO I

Nos 30 anos decorridos entre 1980 e 2010 foram assassinadas no país acima de 92 mil mulheres, 43,7 mil só na última década. O número de mortes nesse período passou de 1.353 para 4.465 , que representa um aumento de $230 \%$, mais que triplicando o quantitativo de mulheres vítimas de assassinato no país.

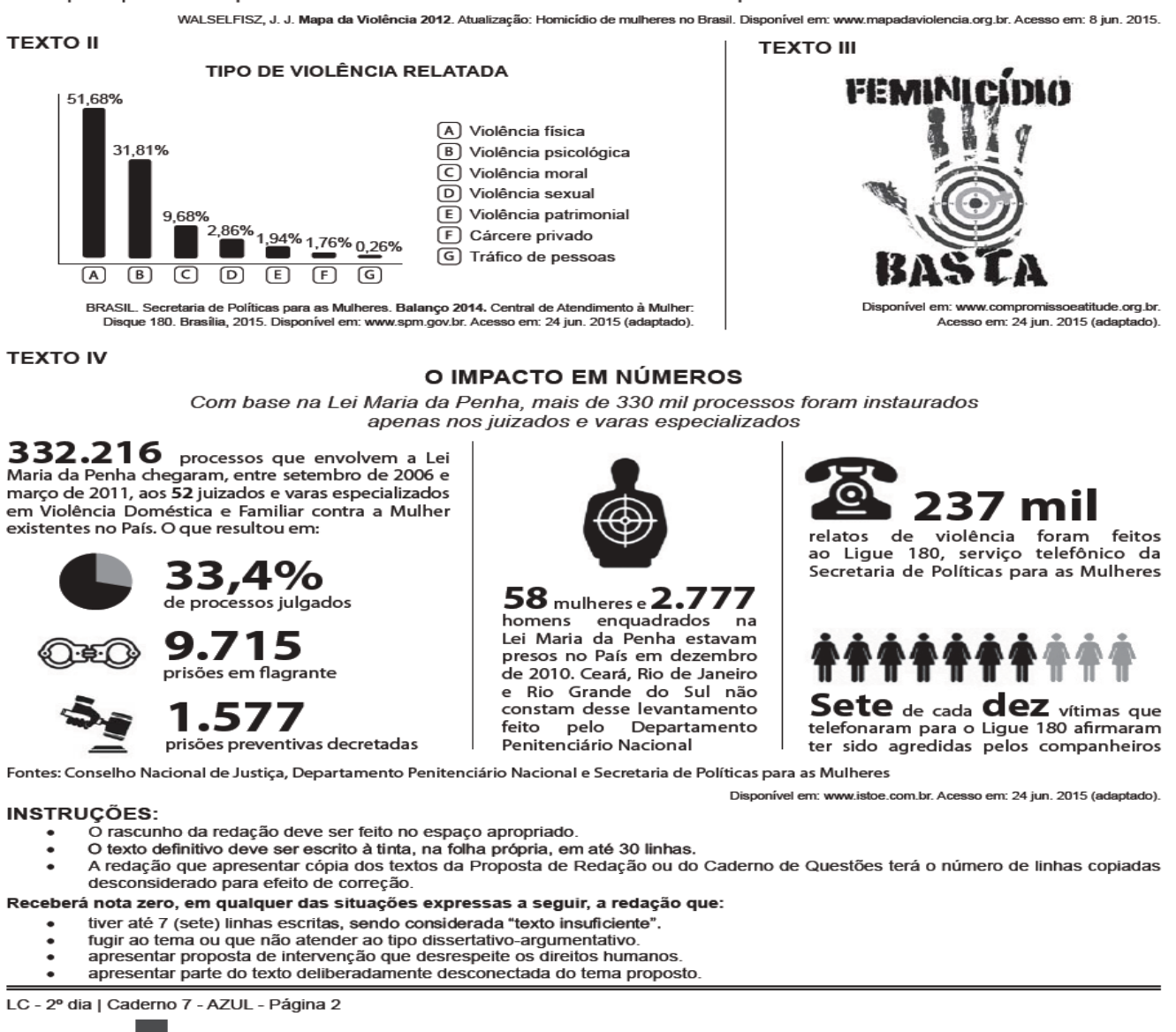

Já sabemos que este é um enunciado que circula em um campo específico de atividade humana no Brasil, o da Educação. Mais particularmente, integra o sistema de avaliação do ensino básico através do ENEM, surgido em 1998, e que passou a selecionar e, ao mesmo tempo, excluir candidatos ao ensino superior. Sabemos também que o conteúdo temático das propostas de redação é elaborado a partir de problemáticas sociais. Nesse sentido, essa proposta teve sua temática elaborada a partir de um problema que, de 
longe, caracteriza a sociedade brasileira: o processo de exclusão e discriminação da mulher, presente em nossa sociedade desde sua formação. É dessa relação direta com a vida que surgem as temáticas das propostas de redação do ENEM. Na de 2015, a tomada de posição que reflete o horizonte ideológico de quem elaborou a proposta é a seguinte: a violência contra a mulher ainda persiste na sociedade brasileira. Para conferir efeito de sentido verdadeiro a esse posicionamento, os elaboradores dessa proposta mobilizaram vozes de outros campos de atividade humana que também defendem a persistência da violência contra a mulher.

Essa proposta de redação também dialoga com o discurso político no cenário brasileiro. Nas redes sociais, ela acentuou as discussões entre posicionamentos axiológicos politicamente divergentes, revelando, assim, que a proposta de redação do ENEM é um enunciado marcado pelo dialogismo. Vejamos algumas réplicas à proposta:

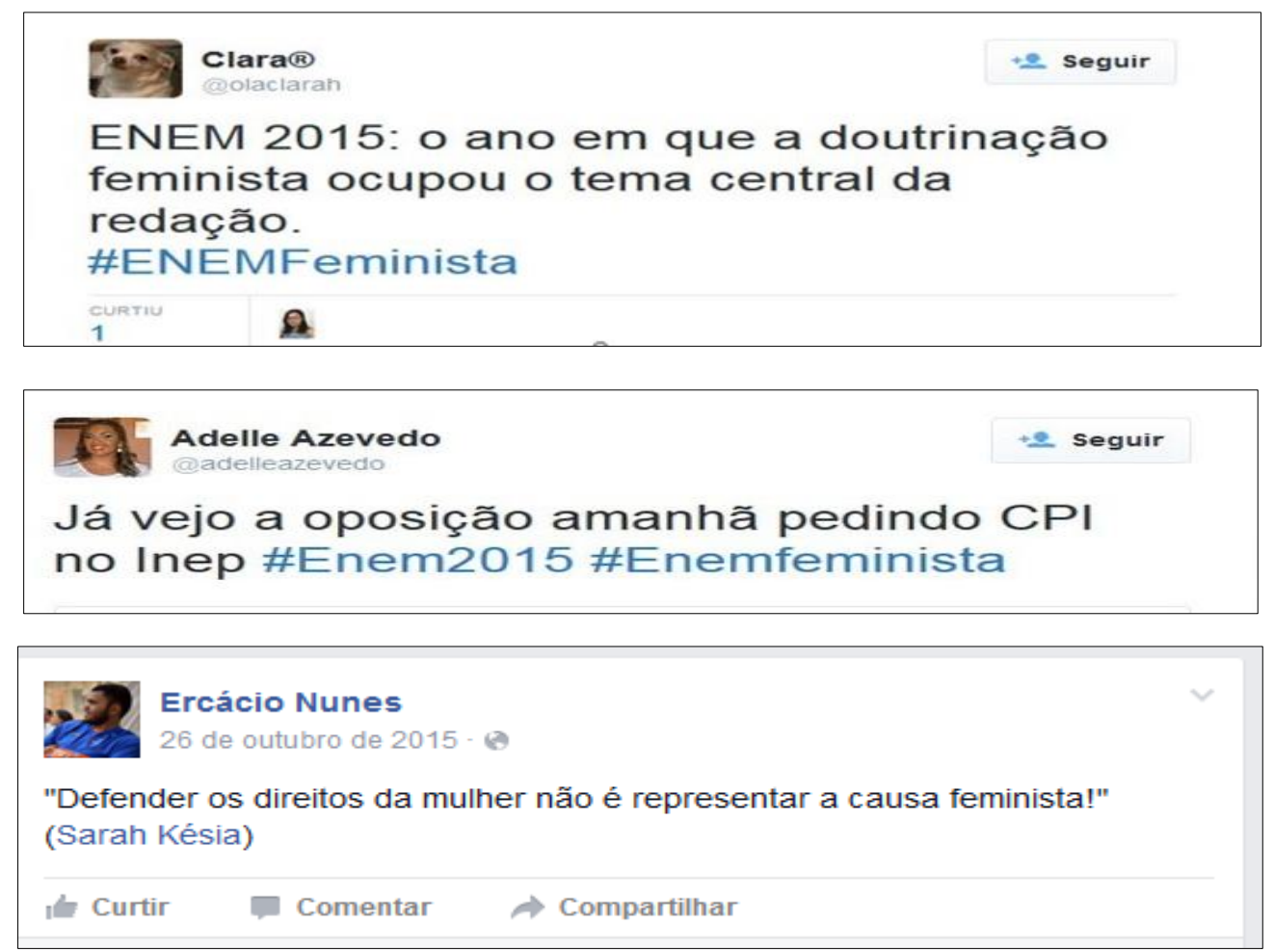

A partir dessas réplicas, fica claro que a proposta foi elaborada em meio à tensão em que figura a política do país. Tensão esta que se revela no embate entre forças políticas de direita e de esquerda. Neste cenário, uma proposta de redação que defenda os direitos da mulher foi imediatamente associada à causa feminista, que se fundamenta em ideais de esquerda. Fora desse reducionismo, há aqueles que se posicionam a favor dos direitos das mulheres, mas que fazem questão de deixar claro que não representam o feminismo, como é o caso do internauta E.N., que, em seu dizer, mobilizou a voz de outra internauta, S.K. A partir dessas réplicas, portanto, percebemos como essa proposta de redação foi elaborada em um espaço de luta entre vozes contrárias, mostrando, assim, que ela é resultado do confronto vivo na arena dos discursos. 
Tendo discorrido sobre aspectos que envolvem a arquitetônica da proposta de redação, como o campo em que ela circula, seus objetivos, seu público-alvo e seus enfrentamentos dialógicos e axiológicos, encerramos esta seção com uma citação de Bakhtin que nos dará a base para as discussões no próximo tópico:

o emprego da língua efetua-se em forma de enunciados (orais e escritos) concretos e únicos, proferidos pelos integrantes desse ou daquele campo da atividade humana. Esses enunciados refletem as condições específicas e as finalidades de cada referido campo não só por seu conteúdo (temático) e pelo estilo da linguagem, ou seja, pela seleção dos recursos lexicais, fraseológicos e gramaticais da língua mas, acima de tudo, por sua construção composicional. Todos esses três elementos - o conteúdo temático, o estilo, a construção composicional - estão indissoluvelmente ligados no todo do enunciado e são igualmente determinados pela especificidade de um determinado campo da comunicação. (BAKHTIN, 2011, p. 261-262; grifos nossos)

\section{A proposta de redação do ENEM: aspectos composicionais}

Os conceitos que destacamos na citação anterior, conteúdo temático, estilo e construção composicional, são, de acordo com o Círculo, os que estabilizam, relativamente, os gêneros do discurso. Por isso, nesta seção, perseguiremos esses três conceitos nas propostas de redações do ENEM.

De modo equivalente às outras propostas de redação, a de 2015 versou sobre uma temática que envolve um problema enfrentado pela sociedade. Além da violência contra a mulher, já foram outros temas de redações: a desvalorização do professor; publicidade infantil; lei seca e o movimento imigratório para o Brasil. Assim, o recorte temático das propostas de redações mantém como base comum o fato de ser feito a partir de problemáticas sociais e atuais da sociedade. A escolha do recorte específico pode variar de acordo com os acontecimentos do ano em que o ENEM é aplicado.

Indissociavelmente ligado ao conteúdo temático, está o estilo, definido por Bakhtin como "a seleção dos recursos lexicais, fraseológicos e gramaticais da língua" (Bakhtin, 2011, p. 261). Vejamos como se materializou, linguisticamente, a primeira parte do enunciado da proposta de redação que, com a variação do tema apresentado, é estável em todas as outras propostas.

A partir da leitura dos textos motivadores seguintes e com base nos conhecimentos construídos ao longo de sua formação, redija texto dissertativo-argumentativo em modalidade escrita formal da língua portuguesa sobre o tema "A persistência da violência contra a mulher na sociedade brasileira", apresentando proposta de intervenção que respeite os direitos humanos. Selecione, organize e relacione, de forma coerente e coesa, argumentos e fatos para defesa de seu ponto de vista. 
Os aspectos linguísticos desse trecho apontam para um enunciado elaborado dentro da tipologia textual injuntiva ${ }^{4}$. Primeiramente, atentemos para os verbos empregados. Redija, selecione, organize e relacione estão todos no imperativo ${ }^{5}$, uma das marcas linguísticas de um tipo de texto injuntivo. Acompanhando esses verbos, aparecem os adjuntos adverbiais de modo em modalidade escrita formal da língua portuguesa e de forma coerente e coesa que, respectivamente, orientam os candidatos para o modo como devem redigir seus textos e como devem selecionar e organizar os argumentos. Além desses termos, a oração subordinada adverbial reduzida de gerúndio apresentando proposta de intervenção que respeite os direitos humanos também instrui os candidatos para o modo como o texto deve ser redigido. Nessa materialidade linguística do enunciado, portanto, o candidato é instruído acerca de o que, como e a partir de que ele deve escrever. Firma-se, assim, uma prática de ensino estabilizada na e pela escola, a de tentar controlar a prática de escrita dos estudantes.

Logo após essa parte puramente injuntiva do enunciado, segue uma sequência de fragmentos de textos que já circularam em outros campos de atividade humana. Mais uma vez, apesar da variação dos fragmentos textuais, a natureza de composição da proposta é a mesma em todas elas. Por vezes, esses fragmentos mesclam o não-verbal ao verbal. A proposta de 2015 foi elaborada a partir de quatro fragmentos de outros textos, cujas fontes são indicadas logo abaixo de cada um.

Essa escolha dos diferentes fragmentos de texto para a formulação do tema faz parte da estratégia do enunciador de se distanciar do objeto de seu discurso. É uma tentativa estilística de conferir objetividade ao tema proposto, como se este não fosse resultado de um posicionamento valorativo. Para essa objetividade, contribui a mobilização de outras vozes. Não é a voz do elaborador da proposta que fala. Quem fala são outras vozes. Entretanto, essas outras vozes resultam de uma seleção feita numa realidade multifacetada. Por meio deste mecanismo de citação de trechos de outros textos, o autor da proposta mantém-se recolhido: valem as outras vozes, citadas com ares de objetividade. Esta é uma marca estilística de todas as propostas.

Assim, esse recorte de fragmentos de outros textos marca, na construção composicional, a mobilização dos argumentos em favor do ponto de vista de quem elaborou o enunciado. É a mobilização de vozes sociais que ratificam o horizonte ideológico marcado na própria proposta de redação. Na composição do gênero, essa mobilização materializa-se pela incorporação de recortes de gêneros de outros campos sociais, como o midiático, o jornalístico e o jurídico. Neste ponto, chegamos à distinção feita por Bakhtin entre gêneros primários e secundários. Diz ele que

os gêneros discursivos secundários (complexos - romances, dramas, pesquisas científicas de toda espécie, os grandes gêneros publicísticos, etc.) surgem nas condições de um convívio cultural mais complexo e

\footnotetext{
${ }^{4}$ Compartilhamos do pensamento de Marcuschi (2005), de que os tipos textuais são definidos por característica da natureza linguística de sua composição, enquanto os gêneros são definidos por características sociocomunicativas.

${ }^{5}$ A partir da teoria de Austin acerca dos enunciados performativos, podemos afirmar que esses verbos no imperativo realizam um enunciado performativo implícito e que, portanto, o enunciador "esconde-se" por meio destes enunciados. Explicitamente, o enunciado performativo ficaria mais ou menos assim: "Eu ordeno que você redija um texto dissertativo-argumentativo". Assim, a categoria de pessoa, nestes enunciados, é instaurada implicitamente, marca estilística de todas as propostas de redação.
} 
relativamente muito desenvolvido e organizado (predominantemente o escrito) - artístico, científico e sociopolítico, etc. No processo de sua formação eles incorporam e reelaboram diversos gêneros primários (simples), que se formaram nas condições da comunicação discursiva imediata. Esses gêneros primários, que integram os complexos, aí se transformam e adquirem um caráter especial: perdem o vínculo imediato com a realidade concreta e os enunciados reais alheios. (BAKHTIN, 2011, p. 263)

Assim, a proposta de redação pode ser classificada como um gênero secundário, uma vez que ela não é elaborada em condições de comunicação discursiva imediata. Pelo contrário, é um enunciado previamente planejado para uma situação relativamente organizada e complexa, a do ENEM. O que nos inquieta neste momento, entretanto, é o recorte de outros gêneros nesse enunciado. Isso porque, segundo Bakhtin, os gêneros secundários incorporam gêneros primários. As propostas de redação, entretanto, incorporam outros gêneros secundários, também elaborados em situações complexas de comunicação discursiva.

Após a sequência com os fragmentos dos textos, é apresentada, em forma de tópicos, uma sequência com instruções para os candidatos, incluindo as situações que podem levá-lo a receber nota zero. Comparando as propostas de $2015 \mathrm{com}$ as anteriores, observamos que essa última sequência com as situações em que é atribuída nota zero modificou a estrutura composicional da proposta, a partir de 2013, ano em que os critérios para a correção da prova ficaram mais rigorosos, porque, em 2012, um candidato inseriu uma receita de macarrão instantâneo em sua redação, e, mesmo assim, recebeu nota 560. Devido à repercussão midiática causada por essa redação, foi acrescentado à proposta 0 tópico que informava que qualquer texto que apresentasse parte deliberadamente desconectada do tema receberia nota zero. Trata-se, portanto, de um fenômeno ligado ao plano arquitetônico do gênero que operou mudanças na estrutura composicional do enunciado.

Acreditamos, agora, que já temos condições de responder à pergunta formulada na introdução.

\section{Considerações finais}

As propostas de redação do ENEM formam um gênero discursivo? Mostramos que elas correspondem a enunciados concretos, que circulam regularmente em um campo específico de atividade humana, marcados por um horizonte ideológico próprio. Mostramos também que a estrutura composicional e o estilo são bastante estáveis nos diferentes enunciados. Quanto à temática, embora haja variação no recorte que é feito, ela é sempre elaborada a partir de problemáticas sociais específicas. Uma vez que os enunciados se agrupam em gêneros discursivos, à pergunta que formulamos na introdução, respondemos afirmativamente.

É importante, nesse sentido, que os candidatos ao ENEM sejam apresentados às propostas de redação entendendo-as como um enunciado no qual a realidade apresentada é apenas um recorte da vida, operado a partir de um posicionamento valorativo de um 
sujeito ideologicamente situado. É importante, também, que eles entendam os mecanismos linguísticos através dos quais a demarcação axiológica é feita nas propostas. Acreditamos que, se ficar claro para os estudantes que elas não abordam a realidade de maneira objetiva, mas veiculam um ponto de vista em uma realidade complexa e heterogênea, eles terão mais autonomia para se posicionar criticamente, concordando ou discordando relativamente ao tema proposto pela prova de redação.

\section{Referências bibliográficas}

BAKHTIN, M. Os gêneros do discurso. Em: Estética da criação verbal. Trad. Bras. São Paulo: Martins Fontes, 2011.

O problema do conteúdo, do material e da forma na criação literária. Em:

Questões de literatura e de estética: a teoria do romance. Trad. Bras. São Paulo: HUCITEC, 2010.

BRAIT, B.; PISTORI, M.H.C. A produtividade do conceito de gênero em Bakhtin e o Círculo, ALFA, São Paulo, 56 (2): 371-401, 2012.

FARACO, C.A. Linguagem e diálogo: as ideias linguísticas do Círculo de Bakhtin. Curitiba: Criar edições, 2003.

INSTITUTO BRASILIRO DE GEOGRAFIA E ESTATÍSTICA. Base de dados do ENEM. Rio de Janeiro, 2015. Disponível em <http://ces.ibge.gov.br/pt/base-dedados/metadados/inep/-nacional-do-ensino-medio-ENEM>; acesso em abril de 2016.

INSTITUTO NACIONAL DE ESTUDOS E PESQUISAS EDUCACIONAIS ANÍSIO TEIXEIRA - INEP. Provas do ENEM 2015. Brasília, 2015. Disponível em <http://download.inep.gov.br/educacao_basica/ENEM/provas/2015/CAD_ENEM\%202 015_DIA\%202_07_AZUL.pdf >; acesso em abril de 2016.

MEDVIÉDEV, P.N. O método formal nos estudos literários: introdução crítica a uma poética sociológica. Trad. Bras. São Paulo: Contexto, 2012.

SOBRAL, A. A estética em Bakhtin: literatura, poética e estética. In. PAULA, L. STAFUZZA, G. (Orgs). Círculo de Bakhtin: teoria inclassificável. Campinas, SP: Mercado de Letras, 2010.

Ético e estético: na vida, na arte e nas pesquisas em Ciências Humanas. Em: BRAIT, B. (Org.) Bakhtin: conceitos-chave. São Paulo: Contexto, 2007.

VOLOSHINOV, V.N. Estrutura do enunciado. [Trad. de Ana Vaz, para fins didáticos. Com base na tradução francesa de Tzvetan Todorov, La strutucture de l'énoncé, 1930, publicada em Tzvetan Todorov: Mikail Bakhtin - Le príncipe dialogique, Paris, Seuil, 1976]. 
Artigo recebido em: abril de 2016.

Aprovado e revisado em: junho de 2016.

Publicado em: agosto de 2016

\section{Para citar este texto:}

SILVA, Joserlândio da Costa. A proposta de redação do ENEM: uma análise arquitetônica e composicional. Entremeios [Revista de Estudos do Discurso], Seção Estudos, Programa de Pós-graduação em Ciências da Linguagem (PPGCL), Universidade do Vale do Sapucaí, Pouso Alegre (MG), vol. 13, p. 139-149, jul. - dez. 2016.

DOI: http://dx.doi.org/10.20337/ISSN2179-3514revistaENTREMEIOSvol13pagina139a149 